\title{
ISSUES IN MEDICINE \\ Prevention of infective endocarditis in developing countries - justifiable caution?
}

\author{
Andy Parrish, Breminand Maharaj
}

The internationally accepted practice of prescribing prophylactic antibiotics to individuals at risk of infective endocarditis has come under scrutiny. There are no published high-quality randomised controlled trials of the intervention, but new insights have emerged. Bacteraemic episodes are common following simple activities such as brushing teeth. Endocarditis following procedures is extremely rare, and systematic reviews of the evidence for prophylactic antibiotics have failed to demonstrate efficacy.

S Afr Med J 2012;102(8):652-654. DOI:10.7196/SAMJ.5688
In both Europe and the USA, guideline bodies have limited their indications for endocarditis prophylaxis. The UK has taken the bolder step of not recommending it at all, but clinicians are appropriately cautious in changing long-established practice. South Africa has a high burden of rheumatic heart disease and HIV, and inappropriate restrictions could have major consequences. However, in areas of high prevalence, it is equally concerning to continue with a practice that may have little benefit and some potential harm.

The CRASH trial ${ }^{1}$ demonstrated that corticosteroid use in head injury was associated with increased mortality. It was estimated that 10000 patients might have died over the previous few decades because of this intervention. ${ }^{2}$ Clinicians had reasoned that although there was no clear evidence of benefit, short-term use seemed unlikely to cause harm. This trial serves as a sobering reminder of the fallibility of intuitive assumptions of benefit based on biological plausibility and weak evidence.

Recently, many guidelines on infective endocarditis (IE) prophylaxis have been revised. The National Institute of Health and Clinical Excellence (NICE) guideline from the UK does not recommend antibiotic prophylaxis in patients with predisposing cardiac conditions undergoing dental and non-dental interventional procedures. ${ }^{3}$ Other guidelines still recommend prophylaxis when the consequences of developing IE are expected to be most severe, or in patients at highest risk. ${ }^{4}$ These recommendations are based on differing interpretations and weighting of the same limited body of evidence.

\section{The evidence}

Dental and endoscopic procedures may cause transient bacteraemia. ${ }^{5}$ IE is sometimes preceded by an interventional procedure, and antibiotics given before such procedures reduce the frequency of positive blood cultures. ${ }^{6}$ Although their validity has been questioned,

Andy Parrish is an Associate Professor at the Department of Internal Medicine, Walter Sisulu University and the East London Hospital Complex. Breminand Maharaj is a Professor at the Department of Therapeutics and Medicines Management, Nelson R Mandela School of Medicine, University of KwaZulu-Natal, Durban. antibiotics reduce the frequency of episodes of IE in some animal models. ${ }^{7}$

Bacteraemia detectable by blood culture may occur after more than $20 \%$ of toothbrushing episodes, ${ }^{8}$ with even higher frequencies in individuals with suboptimal dental hygiene. ${ }^{9}$ IE can develop despite prophylaxis. ${ }^{10}$ Extractions are often performed because of dental sepsis, and it is conceivable that the underlying condition produces more cumulative bacteraemic episodes than the treating intervention. ${ }^{11}$

A 2004 Cochrane review, and a 2008 update, ${ }^{12}$ failed to identify any blinded randomised controlled trials (RCTs) on IE prophylaxis but found 4 case control studies. Two studies ${ }^{13,14}$ were felt to be biased as information on antibiotic use was unavailable for more than $20 \%$ of the case patients. A third study included very low-risk patients. ${ }^{15}$ The remaining case control study ${ }^{16}$ did not support a protective effect of antibiotic use, and even pooling this with the two studies excluded because of bias did not show benefit.

Agha et al. ${ }^{17}$ pooled all 4 case control studies, regardless of their drawbacks, to derive a non-significant odds ratio (OR) of 0.46 ( $95 \%$ confidence interval (CI) 0.2 - 1.1). Although the effect size is large, benefit was again unproven.

\section{The NICE economic model}

The OR of 0.46 from the Agha model was used in the NICE economic mode ${ }^{18}$ to provide an estimated $50 \%$ relative risk reduction. Most modelling of the cost-effectiveness of new medications would stop here. If efficacy - the denominator - is not demonstrated to exclude a null effect, then the cost-effectiveness ratio is undefined.

The risk of an individual with a predisposing cardiac condition developing IE after a procedure was set at 4.1 per million interventions. This rate appears to be derived from a calculation in a previous economic mode ${ }^{19}$ that specifically addressed patients with mitral valve prolapse, and calculated its estimates based on work from the 1970s. In natural frequencies, the base case estimate of 4.1 per million is the same as 1 in 250000 , increasing to at most 1 in 10000 for patients with prosthetic valves.

The probability of fatal anaphylaxis after oral amoxicillin was set at zero (no harm) in the model base case.

A multi-national study ${ }^{20}$ (Hungary, Spain, India and Sweden) reported 6 (95\% CI 2.4 - 15) cases of anaphylaxis per 100000 individuals treated with oral amoxicillin. Mortality rates for amoxicillin-associated anaphylaxis are poorly defined, with concerns about under-reporting. ${ }^{21}$ For anaphylaxis in general, mortality is estimated to be less than $1 \% .{ }^{22}$ Assuming amoxicillin-associated anaphylaxis is no different to other aetiologies, fatal anaphylaxis 
after oral amoxicillin might be expected in less than one in a million patients. An earlier cost-effectiveness study used a figure of 0.9 per million. ${ }^{23}$

\section{Model results - NICE}

In the NICE base case analysis, 21 cases of IE would be prevented for every 10 million patients given prophylaxis in the presence of a predisposing cardiac condition. To prevent one death from IE, one would need to treat 2.5 million people. Using the same model, if ongoing prophylaxis of $50 \%$ efficacy is continued for a lifetime (mean of 1.5 dental procedures per year), the NICE group estimated a mean quality adjusted life year (QALY) accrual per person of 50 minutes over a 50-year time horizon. The cost per QALY was $£ 204000$, which is well above the conventional NICE cut-off of $£ 30000$ per QALY. The model was able to demonstrate cost-effectiveness for patients at high risk (e.g. those with prosthetic valves) but even then only using generous risk assumptions.

In the UK, scripts for prophylactic antibiotics for IE fell sharply after release of the NICE recommendations, without a significant alteration in IE incidence. ${ }^{24}$ In the tangled terminology of noninferiority studies, this early review excluded a rise in incidence of more than $9.3 \%$, which was less than the pre-set value of $15 \%$ (determined by background data fluctuations). An alternative explanation for the unchanged rate might be that high-risk patients in the UK continue to be prescribed antibiotics despite the new recommendations. ${ }^{25}$

\section{Variations in international guidelines}

The French IE prophylaxis guideline of $2002^{26}$ was followed by a British Antimicrobial Society report in 2006, ${ }^{27}$ and the American Heart Association guideline of 2007. ${ }^{4}$ In 2008, NICE ${ }^{28}$ suggested the practice be suspended completely. In 2009, the European Society of Cardiology still recommended prophylaxis for high-risk individuals in line with the AHA guidelines. ${ }^{29}$

A further variation arose in the Australasian guidelines, ${ }^{30}$ where prophylaxis was still recommended in 'Indigenous Australians' with rheumatic heart disease, based on expert opinion that the condition was more severe in this group.

\section{The published debate}

There is now almost a decade's worth of lively commentary following common themes that can be grouped according to shortcuts and pitfalls in our thinking (the taxonomy of heuristics and biases): $:^{31,32}$

1. Denial of any evidence - statements suggesting that in the absence of RCTs, decision making is essentially arbitrary. In one instance, there was outright refusal even to read the evidence. ${ }^{33}$ Evidencebased medicine (EBM) advocates using the best available evidence, but acknowledges that sometimes only observational studies are available.

2. Causal schema bias - a tendency to be more comfortable with explanations incorporating a causal narrative (bacteraemia causes IE; antibiotics reduce bacteraemia; therefore antibiotics reduce endocarditis). This 'coherent' explanation is appealing to many clinicians. ${ }^{34}$

3. Group think - adopting beliefs shared by a group. A shared and strongly endorsed guideline gains credibility. ${ }^{35}$

4. Fundamental attribution error - ignoring alternative explanations for endocarditis after an intervention. ${ }^{36}$

5. Honouring sunk costs - because we have 'always' done this, it may be worth continuing to invest in the strategy. ${ }^{37}$

6. Availability heuristic - vivid cases override balanced recollection (we remember the active sportsperson who developed an
IE-associated stroke after a tooth extraction, ${ }^{38}$ but fail to recall the many other patients who didn't).

7. Ad hominem arguments - disparaging the individual presenting the argument. ${ }^{39}$

8. Risk aversion and asymmetrical value assignments (valuing potential losses higher than gains) - potential gains from limiting the overuse of antibiotics and avoiding anaphylaxis are seen to be less tangible than the potential occurrence of an avoidable episode of IE. ${ }^{40}$

\section{Practical belief revision}

Coherence-correspondence models of thinking may explain some of the resistance to paradigm shifts described by Kuhn. ${ }^{41}$ Coherence emphasises the existence of a logical explanatory narrative whereas correspondence focuses more on empiric observation, with greater tolerance for gaps in understanding. Both models have led to important advances in medicine. ${ }^{42}$ Of 124 articles in one journal in 2009, $13 \%$ were considered 'reversals' - new higher quality trials that contradicted current practice. ${ }^{43}$ Initial adoption on the basis of physiological principles (coherence) rather than sound evidence was a common theme among the reversals.

One cognitive crutch recognises the limited half-life of medical truth. ${ }^{44-47}$ We might change our learning mindset, which from medical school days has always been acquisitive (What new things did I learn today?) to include the countervailing question (What mistaken belief have I relinquished today?).

Shifting between the coherence and correspondence models may also be of value. In the current example, paying attention to the cracks in the smooth narrative of biological plausibility can be punctuated by a review of the (very limited!) numeric information.

\section{Local applicability}

When international guidelines looking at the same body of evidence make differing recommendations, it becomes particularly important to achieve local clarity. It may be reasonable to argue that developing countries in Africa lack the resources to re-explore the evidence and develop their own guidelines, although adaptation of international guidelines may be feasible. ${ }^{48-50}$ Such adaptations should acknowledge local factors, e.g. the high prevalence of rheumatic heart disease and $\mathrm{HIV}$, and potentially greater IE severity owing to late presentation and differing causes of valvular damage. However, these factors affect policy effectiveness rather than efficacy. If IE prophylaxis works, then a policy of using it will benefit more individuals in areas of high prevalence and severity; if it doesn't work, and is being given to many people, there is potential for more harm.

\section{Future directions}

Further debate culminating in a consensus position on IE prophylaxis in developing countries would be helpful. Prophylaxis has modest - if any - value, but a trial six times the size of CRASH would be needed to establish clearly whether it does more good than harm. It seems unnecessary to retain the traditional recommendations when NICE, AHA and ESC have already revised their stance, but changing established belief takes time. A pragmatic approach might be to emphasise both good dental hygiene and early recognition and treatment of established endocarditis, and to de-emphasise reliance on an intervention of uncertain benefit.

\footnotetext{
1. CRASH trial collaborators. Effect of intravenous corticosteroids on death within 14 days in 1000 adults with clinically significant head injury (MRC CRASH trial): randomised placebo-controlled trial. adults with clinically significant head injury (MRC CRASH trial): randomised pla

Sauerland S, Maegele M. A CRASH landing in severe head injury. Lancet 2004;364:1291-1292. [http:// Sauerland S, Maegele M. A CRASH landing in severe he
dx.doi.org/10.1016\%2FS0140-6736\%2804\%2917202-4]
} 
3. NICE Short Clinical Guidelines Technical Team. Prophylaxis against infective endocarditis: antimicrobial prophylaxis against infective endocarditis in adults and children undergoing antimicrobial prophylaxis against infective endocarditis in adults and children undergoing
interventional procedures. National Institute for Health and Clinical Excellence Clinical Guideline 64, Mar 2008. http://www.nice.org.uk/CG064. (accessed 19 March 2012).

4. Wilson W, Taubert KA, Gewitz M, et al. Prevention of Infective Endocarditis: Guidelines from the American Heart Association. Circulation 2007;116:1736-1754. [http://dx.doi.org/10.1161\%2FCIRCU ATIONAHA 106.183095]

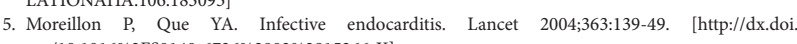
org $10.1016 \% 2$ FS0140-6736\%2803\%2915266-X

6. Khairat $\mathrm{O}$. An effective antibiotic cover for the prevention of endocarditis following dental and other post-operative bacteraemias. J Clin Path 1966;19:561-566.[http://dx.doi.org/10.1136\%2Fjcp.19.6.561] 7. Carmona IT, Diz Dios P, Scully C. Efficacy of antibiotic prophylactic regimens for the prevention of bacterial endocarditis of oral origin. J Dent Res 2007;86:1142-1159. [http://dx.doi.org/10.1177\% 2F154405910708601203

8. Lockhart PB, Brennan MT, Sasser HC, Fox PC, Paster BJ, Bahrani-Mougeot FK. Bacteremia associated with toothbrushing and dental extraction. Circulation 2008:117:3118-3125. [http://dx doi org/10.1161 \%2FCIRCULATIONAHA.107.758524]

9. Lockhart PB, Brennan MT, Thornhill MH, et al. Poor oral hygiene as a risk factor for infective endocarditis-related bacteremia. I Am Dent Assoc 2009:140:1238-1244. http://jada.ada.org/cgi/ content/full/140/10/1238 (accessed 19 March 2012).

10. Durack DT, Kaplan EL, Bisno AL. Apparent failures of endocarditis prophylaxis. Analysis of 52 cases submitted to a National Registry. JAMA 1983:250:2318-2322. [http://dx.doi. org/10.1001\%2Fjama.250.17.2318]

1. Duval X, Leport C. Prophylaxis of infective endocarditis: current tendencies, continuing controversies. Lancet Infect Dis 2008;8:225-232. [http://dx.doi.org/10.1016\%2FS1473-3099\%2808\%2970064-1]

12. Oliver R, Roberts GJ, Hooper L, Worthington HV. Antibiotics for the prophylaxis of bacterial endocarditis in dentistry. Cochrane Database Syst Rev 2008 Oct 8;(4):CD003813. [http://dx.doi. org/10.1002\%2F14651858.CD003813.pub3]

13. Lacassin F, Hoen B, Leport C, et al. Procedures associated with infective endocarditis in adults. A case control study. Eur Heart J 1995;16:1968-1974.

14. Imperiale TF, Horwitz RI. Does prophylaxis prevent postdental endocarditis? A controlled evaluation of protective efficacy. Am I Med 1990;88:131-136. [http://dx.doi.org/10.1016\%2F0002$9343 \% 2890 \% 2990461-\mathrm{L}$

15. Strom BL, Abrutyn E, Berlin JA, et al. Dental and cardiac risk factors for infective endocarditis. A population based, case-control study. Ann Intern Med 1998:129:761-769.

16. Van der Meer JT, van Wijk W, Thompson J, Vandenbroucke JP, Valkenberg HA, Michel MF. Efficacy of antibiotic prophylaxis for prevention of native-valve endocarditis. Lancet 1992;339:135-139.

17. Agha Z, Lofgren RP, van Ruiswyk JV. Is antibiotic prophylaxis for bacterial endocarditis cost-effective? Med Decis Making 2005;25:308-320. http://mdm.sagepub.com/content/25/3/308.refs.html (accessed 19 March 2012).

8. NICE Short Clinical Guidelines Technical Team. Prophylaxis against infective endocarditis antimicrobial prophylaxis against infective endocarditis in adults and children undergoing interventional procedures. NICE Clinical Guideline 64, Appendices. Mar 2008. http://www.nice.org. uk/CG064 (accessed 19 August 2011).

19. Clemens JD, Ransohoff DF. A quantitative assessment of pre-dental antibiotic prophylaxis for patients with mitral-valve prolapse. J Chronic Dis 1984;37:531-544. [http://dx.doi.org/10.1016\% 2F0021-9681\%2884\%2990004-3]

20. Kaufman DW, Kelly JP. Risk of anaphylaxis in a hospital population in relation to the use of various drugs: an international study. Pharmacoepidemiology and Drug Safety 2003;12:195-202. [http:// drdo.

21. Pumphrey RS, Davis S. Under-reporting of antibiotic anaphylaxis may put patients at risk. (Letter) Lancet 1999;353:1157-1158. [http://dx.doi.org/10.1016\%2FS0140-6736\%2899\%2900449-3]

22. Bjornsson HM, Graffeo CS. Improving diagnostic accuracy of anaphylaxis in the acute care setting. West J Emerg Med 2010;11:456-461.

23. Devereux RB, Frary CJ, Kramer-Fox R, Roberts RB, Ruchlin HS. Cost-effectiveness of infective endocarditis prophylaxis for mitral valve prolapse with or without a mitral regurgitant murmur. Am Cardiol 1994;74:1024-1029. [http://dx.doi.org/10.1016\%2F0002-9149\%2894\%2990853-2]

24. Thornhill MH, Dayer MJ, Forde JM, et al. Impact of the NICE guideline recommending cessation of antibiotic prophylaxis for prevention of infective endocarditis: before and after study. BM] 2011:342:d2392. [http://dx.doi.org/10.1136/bmj.d2392]

25. Chambers JB, Shanson D, Venn G, Pepper I. Nice v world on endocarditis prophylaxis. BM 2011:342:d3531. [http://dx_doiorg/10.1136\%2Fbmj.d3531]
26. Danchin N, Duval X, Leport C. Prophylaxis of infective endocarditis: French recommendations 2002. Heart 2005;91:715-718. [http://dx.doi.org/10.1136\%2Fhrt.2003.033183]

27. Gould FK, Elliott TS, Foweraker J, et al. Guidelines for the prevention of endocarditis: report of the Working Party of the British Society for Antimicrobial Chemotherapy. Antimicrob Chemother 2006;57:1035-1042. [http://dx.doi.org/10.1093\%2Fjac\%2Fdkl121]

28. National Institute for Health and Clinical Excellence. Prophylaxis against infective endocarditis. NICE Clinical Guideline 2008. http://www.nice.org.uk/CG064 (accessed 19 March 2012).

29. The Task Force on the Prevention, Diagnosis and Treatment of Infective Endocarditis of the European Society of Cardiology. Guidelines on the prevention, diagnosis and treatment of infective endocarditis. Eur Heart J 2009;30:2369-2413. [http://dx.doi.org/10.1093/eurheartj/ehp285]

30. Moulds RFW, Jeyasingham MS, for the Infective Endocarditis Prophylaxis Expert Group, Therapeutic Guidelines Ltd. Antibiotic prophylaxis against infective endocarditis: time to rethink. Med J Australia 2008; 189:301-302.

31. Bornstein BH, Emler AC. Rationality in medical decision making: a review of the literature on doctors' decision-making biases. J Evaluation Clin Practice 2001;7:97-107. [http://dx.doi. org/10.1046\%2Fj.1365-2753.2001.00284x

32. Croskerry P. Achieving quality in clinical decision making: cognitive strategies and detection of bias. Academic Emergency Med 2002;9:1184-1204. [http://dx.doi.org/10.1197\%2Faemj.9.11.1184]

33. Friedlander AH. Antibiotic prophylaxis. (Letter). J Am Dent Assoc 2009;140:1347-1348. [http://jada. da.org/content/140/11/1347.2.long

34. Gibbs JL, Cowie M, Brooks N. Defying explanation. Br Dent J 2006:201:188.

35. Embil JM, Chan K. The American Heart Association 2007 endocarditis prophylaxis guidelines: a compromise between science and common sense. Can J Cardiol 2008;24:673-675. [http://dx.doi. org $/ 10.1016 \% 2 \mathrm{FS} 0828-282 \mathrm{X} \% 2808 \% 2970664-0$

36. Biswas S, Bowler IC, Bunch C, Prendergast B, Webster DP. Streptococcus mutans infective endocarditis complicated by vertebral discitis following dental treatment without antibiotic prophylaxis. J Med Microbiol 2010;59:1257-1259. [http://dx.doi.org/10.1099\%2Fjmm.0.020974-0]

37. Whatling PJ, Robb JD, Byrne J, Wendler O. Can we really do without antibiotic prophylaxis for infective endocarditis? BMJ Case Reports 2011;1:bcr0320113949. [http://dx.doi. org $/ 10.1136 \% 2 \mathrm{Fbcr} .03 .2011 .3949$

38. Ramsdale DR, Egred M, Palmer ND, Chalmers JA. Letter. [http://my.americanheart.org/idc/groups/ ahamah-public/@wcm/@sop/documents/downloadable/ucm_319816.pdf]

39. Ramsdale DR, Palmer ND. Antimicrobial prophylaxis for endocarditis: emotion or science? (Letter) Heart 2007;93:753.

40. Cunha BA, D'Elia AA, Pawar N, Schoch P. Viridans streptococcal (Streptococcus intermedius) mitral valve subacute bacterial endocarditis $(\mathrm{SBE})$ in a patient with mitral valve prolapse after a dental procedure: The importance of antibiotic prophylaxis. Heart and Lung: J Acute and Critical Care 10;39:64-72. [http://dx.doi.org/10.1016\%2Fj.hrtlng.2009.01.004]

41. Kuhn, TS. The structure of scientific revolutions. Chicago, IL: University of Chicago Press, 1962.

42. Tape TG. Coherence and correspondence in medicine. Judgment and Decision Making 2009;4:134140

3. Prasad V, Gall V, Cifu A. Research letter. The frequency of medical reversal. Arch Intern Med 2011;171:1675-1676. [http://dx.doi.org/10.1001\%2Farchinternmed.2011.295]

44. Philips Z, Claxton K, Palmer S. The half-life of truth: what are appropriate time horizons for research decisions? Medical Decision Making 2008;28:287-299. [http://dx.doi. org/10.1177\%2F0272989X07312724]

45. Ioannidis JP. Contradicted and initially stronger effects in highly cited clinical research. JAMA 2005:294:218-228.

46. Poynard T, Munteanu M, Ratziu V, et al. Truth survival in clinical research: an evidence-based requiem? Ann Intern Med 2002;136:888-895

47. Poynard T, Thabut D, Munteanu M, Ratziu V, Benhamou Y, Deckmyn O. Hirsch index and truth survival in clinical research. PLOS ONE 2010;5(8):e12044. [http://www.plosone.org/article/ info\%3Adoi\%2F10.1371\%2Fjournal.pone.0012044]

48. Brouwers MC, Kho ME, Browman GP, et al. AGREE II: Advancing guideline development, reporting and evaluation in healthcare. J Clin Epidemiol 2010;63:1308-1311.

49. The ADAPTE Collaboration. The ADAPTE process: Resource toolkit for guideline adaptation. Version 2.0 (2009). http://www.g-i-n.net (accessed 19 March 2012).

50. English M, Opiyo N. Getting to grips with GRADE - perspective from a low-income setting. J Clin Epidemiol 2011;64:708-710. [http://dx.doi.org/10.1016\%2Fj.jclinepi.2010.07.016] 